\title{
Analysis on China's Real Estate Economy Based on Big Data
}

\author{
Weiwei Liu $^{1}$ \\ ${ }^{1}$ Sentinel Secondary School 1250 Chartwell Dr, West Vancouver, BC V7S 2R2 BC, Canada
}

\begin{abstract}
Over the past 40 years of China's reform and opening -up, the Chinese society and national economy have been booming. The real estate economy as a pillar industry of the national economy has achieved rapid growth. However, the U.S. subprime mortgage crisis in 2007, COVID-19 and the intensifying China-US trade war in 2020 have repeatedly raged, like the "Three Sword of Damocles" hurting Chinese economy. Based on rencent 10 years data collection, the paper analyzes the trend of real estate prices and puts forward countermeasures from many aspects to achieve to stabilize the housing market, economic and social situation.
\end{abstract}

\section{INTRODUCTION}

Forty years after China's reform and opening up, the real estate economy as a pillar industry of the national economy has development rapidly.[1]With the existence of the estate bubble in recent years, China's estate economy has entered the stage of "Houses are used to live in, not to be used for speculation." The introduction of relevant government measures has effectively curbed the soaring housing prices. Simultaneously, the domestic and foreign situation that China faces also had a new change. The emergence of these new changes will inevitably have a profound impact on the future real estate economy.

\section{ANALYSIS}

\subsection{The Sword of Damocles}

The 1980s U. S. subprime mortgage crisis has cast a shadow on the U. S. and the world economy. Since last year, Sino-US bilateral frictions and restrictions on China's industrial cooperation by many countries. These new domestic and international changes, whether from the political and social level or the economic and industrial level, will impact China's real estate economic reform in different ways, forming the "Three Sword of Damocles."

First, the U. S. subprime crisis. The U.S. subprime crisis originated in the U.S. subprime sector, where subprime mortgages are known as "subprime mortgages." The subprime mortgage crisis loomed from February 2007 to 2009, triggering the Asian financial turmoil, which caused various degrees of disaster to the United States and the rest of the world.

Second, the Sino-US trade war. China-US relations have grown from the earliest trade disputes between China and the U.S. to the China-US trade war that began in 2018. The area of dispute has also spread from the former microeconomy to areas such as exchange rates, intellectual property, trade inequalities, and national security. Even in recent days, there has been a serious withdrawal of consulates between the two countries, unprecedented in the history of the two countries.

Third, COVID-19. Since January, the COVID-19 outbreak has affected dozens of countries and regions, as of August 04, 2020, the global confirmed 18,380,616 people, 696,389 deaths. [2] Until now, there is still no effective containment in medicine; humans can only respond passively.

\subsection{Impact on China's real estate economy}

\subsubsection{Impact of US subprime mortgage crisis on China's real estate economy:}

The real estate economy is inseparable from credit finance. The real estate economy is extremely sensitive to any changes in credit finance, and it is difficult for the real estate economy to be accompanied by credit finance to sustain. To promote the development of the real estate economy, solve the problems that house purchasers lacked self-owned funds and actively develop individual consumption credit, China introduced the internationally accepted concepts of loans for purchasing houses and mortgage [3]. China's housing market began to enter the price increase range. Under the guidance of real estate for many years [4], many credit funds swarmed the housing market, loan speculation, and leverage effect flooded the housing market, repeating the early consumption of the U.S. subprime mortgage crisis, and speculators overnight rich. 
Facing rising house prices, the Chinese government actively intervenes in the real estate industry utilizing financial credit, blocking the entry of credit funds into the housing market on time, thoroughly suppressing excessive house prices, and effectively squeezing out speculators. However, the use of strict credit policy has also curbed the liquidity needed for real estate. The consequences of the U.S. subprime crisis are bound to reoccur when the housing market's effective purchasing power fails to rise, even as social purchase decreasing due to the Sino-US trade war and the COVID-19.

\subsubsection{Impact of Sino-US Trade War on China's Real Estate Economy:}

The trade war between China and the U.S. is no longer simply a trade war. The longer the trade war lasts, the more controversies the US currently exist, which has led to China's foreign trade industry, processing industry, cutting-edge technology industry, and Huawei 5G industry leaders cannot connect with the world. On the one hand, these enterprises will inevitably lay off their employees, which will make the purchasing of the real estate buyers plummet and cause a panic collapse of the real estate industry, upstream and downstream industries, and even the banking industry. On the other hand, the collapse of real economies will break the industrial chain in which they are located, causing a "domino effect" to drive more enterprises to close down, which will inevitably lead to social economic and social order chaos.

\subsubsection{Impact of the COVID-19 on China's Real Estate Economy.}

Since January of 2020, due to the raging of the new crown epidemic, the transportation and tourism, catering and entertainment industries, retail and department stores, factory stores, and the industrial chain around the world have been hit hard. The capital has accumulated with low investment. Chinese small and medium-sized enterprises cannot bear the financial burden of closing their doors and going out of business. Workers who have no jobs to play have to pay back their house loans while they are struggling.

Above three "The Sword of Damocles" impacting on China's real estate economy will affect or even cut a certain company or industry to some extent. They will attack company's upstream and downstream industries and related industry then swept the real estate demand, supply, financial credit and other parts under "domino effect". The far-reaching impact on Chinese real estate economy should not allow us to be blindly optimistic.

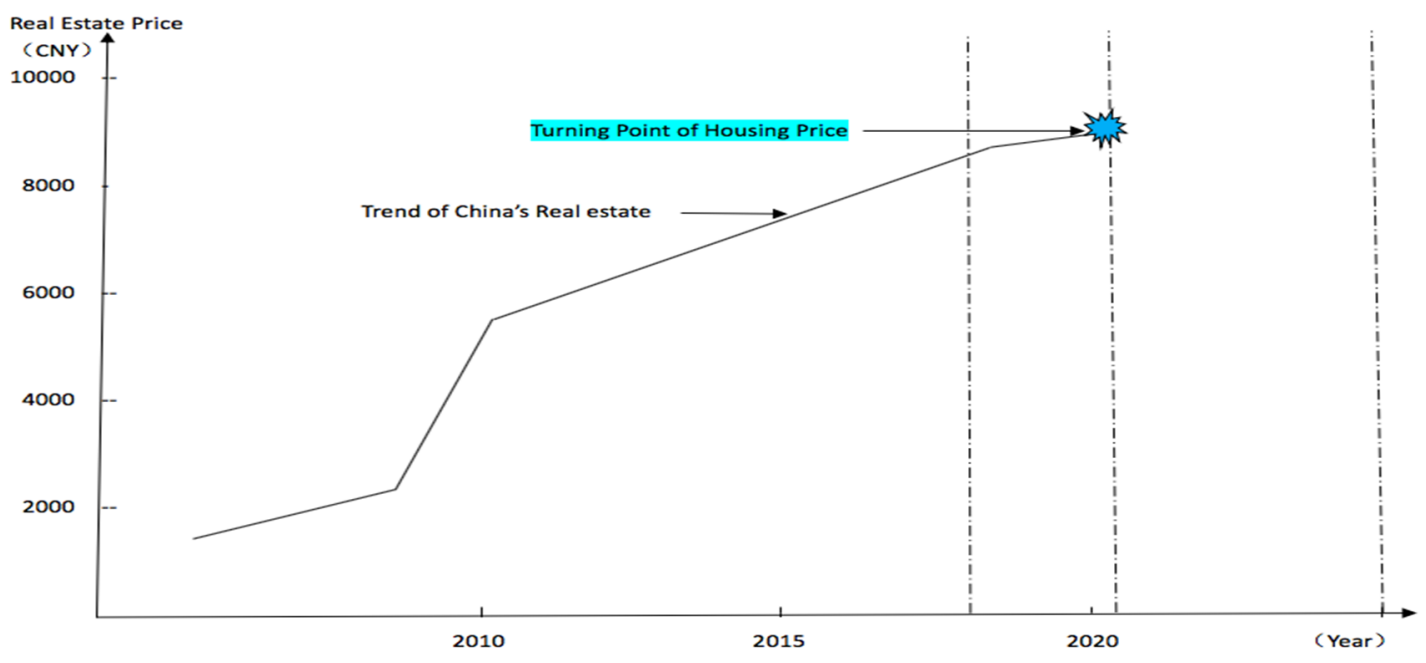

Fig 1. The Trend of Real Estate Prices in China Recent 10 Years 


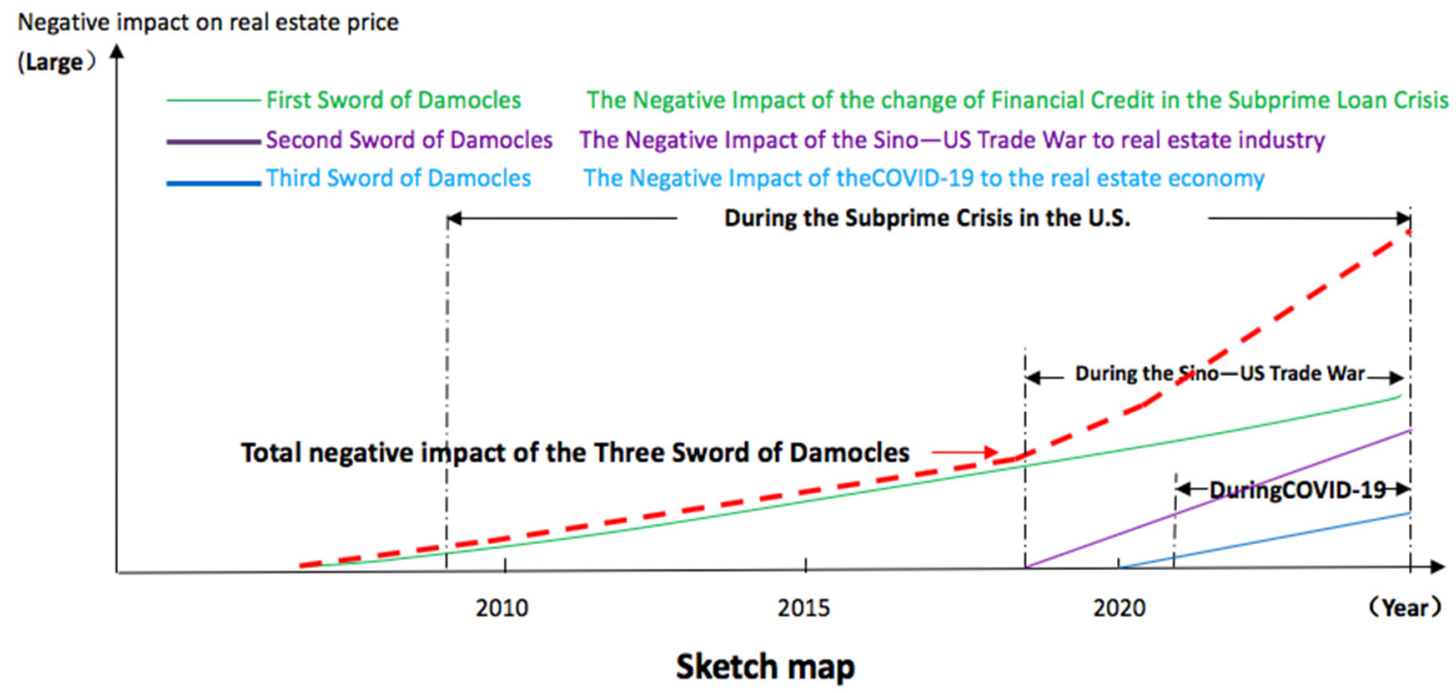

Fig 2. The Negative Impact of Subprime Crisis in U.S., Sino-US Trade War and COVID-19

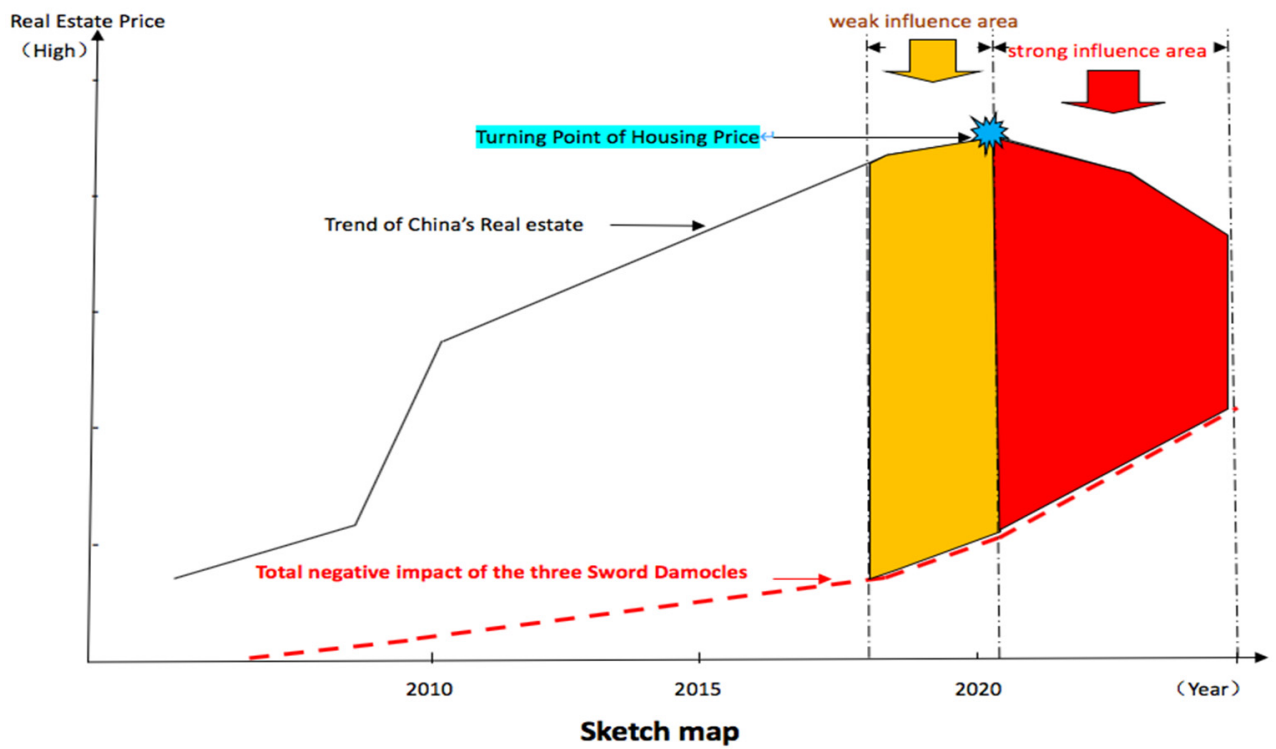

Fig 3. Sketch Map of the Impact on China's Real Estate Price Trend

\subsection{Measures to Reduce the Sharp Decline of Real Estate Prices}

"Live in Peace and Work in Contentment" is the habit of the Chinese people. The number of middle-age people occupies a large proportion of the people who buy houses with loans. Once the three "swords" cut off the source of financial loans to purchase homes, banks will produce many bad loans, which will lead to the economic and social instability. Introducing timely measures to curb the sharp fall in house prices is indeed urgent.

\subsubsection{Using administrative means to strictly control real estate market prices.}

Strong and effective administration is the usual way the Chinese government controls the market. It is more efficient and powerful under the situation of imperfect legal system, which can be proved by the effective control of COVID-19. At that time, Chinese real estate economy's vigorous development benefits from launching a series of policies to guide and then promulgated supporting measures. Now the characteristics of market economy should be fully utilized.

a) The primary real estate market shall be subject to increased construction with guaranteed prices.

In other words, this means that local governments should make corresponding judgments based on real estate prices in their respective regions, combined with the GDP and the economic development of the year. Under the premise of ensuring social stability, credit and financial security, and controllable housing prices, determine the lowest selling prices in the local new housing market at different times, and meet with responsible real estate developers to ensure the lowest transaction prices. The development enterprise can cooperate with the local real estate administrative authorities, compensate for the developer's losses through adjustment of land use quota, planning quota, construction quota to attain effective government control over real estate market prices.

b) Control of guidance on the secondary housing market.

The purchasers of the secondary market are mainly individuals and are numerous with different personnel 
levels. If the implementation of mandatory policies is hard to implement, it is advisable to introduce guiding and effective policies. Such as exempting housing transaction fees during real estate transaction registration, guiding buyers and sellers of second-hand houses to quote actual prices, and eliminating buyers and sellers To avoid paying too much housing transaction fees in proportion to the total housing transaction price, high prices and low prices are reported.

c) Regulation of housing agents.

It is prohibited to post the sale prices and dumping prices of low-priced houses. It is prohibited to incite housing purchasers and sellers to understate prices or conceal actual transaction prices utilizing inducement, suggestion, or inducement. Intermediaries are prohibited from releasing and spreading any information that may weaken market prices. Relevant departments improve the access conditions of housing agencies and gradually reduce housing agencies in the rectification process.

For developers that ignore the management and control of the real estate, they violate government regulations by selling at low prices. The leaders of the enterprises and the enterprises' responsibilities shall be investigated. The contract, document, and financial transaction with the affiliated enterprises and individuals shall be thoroughly investigated; the maximum penalty shall be imposed based on the found violation of laws and regulations. Such problems shall be publicly notified within the industry to achieve the effect of eliminating illegal acts.

\subsubsection{Raise the utilization rate of unoccupied houses through multiple channels and speed up the flow of social funds.}

New government offices shall be reduced or halted in a planned way, and vacant public housing shall be rented out. The vacancy rate shall be increased to make the best use of every item of idle public housing. On the other hand, and government expenditure on new public housing shall be gradually reduced in the face of an economic downturn, thereby increasing the social efficiency of government funds and the liquidity of public funds. Finally, it can also decline the supply stock, the percentage of low-price housing transactions, and the impact of statistics. The government launched the "rent instead of purchase" policy. The developer would be exempted from taxes and fees arising from altering the vacant premises held by it into real properties for rent. The areas with good financial income may try to moderately return the one-off land assignment fee paid by the developer. Also, the local government departments could make up the land assignment fee based on a certain proportion of its annual income from holding the property.

\subsubsection{Other Control Measures. Strictly control the statistics and release of real estate data is another measure to control the real estate market prices.}

The qualifications of the main entities responsible for the statistics and release of real estate data shall be specified. Any entity without the approval is prohibited from illegal statistics or releasing real estate statistical information. The entities and individuals whose statistics or release of real estate information in violation of the regulations cause public panic or real estate market price fluctuation should bear the corresponding responsibility.

For example, reducing the transaction deed tax [5], transaction fees and personal income tax of high-priced houses and small-scale houses [6], from the composition of the real estate market transaction tax and fee, affects the price changes of the actual transaction of house prices, and restrains the rate of decline in house prices.

\section{Conclusion}

Based on the subprime mortgage crisis, Sino-US trade war and COVID-19, this paper predicts that China's social and economic environment will be more dangerous in the next few years. Therefore, the comprehensive application of various means to slow down the sharp fall in house prices is a vital personal point of view. It further briefly expounds the different countermeasures respectively for the primary market, secondary market, and intermediary market in the link of real estate circulation by administrative means to strictly control the prices of the real estate market. The government departments should reduce or suspend the construction of new office buildings utilizing prohibitions in public decrees, and rent or purchase vacant buildings in society instead; They introduce "renting in substitution of purchase," reduce and exempt the property developer may hold the tax. Raise the utilization rate of unoccupied houses through multichannels and speed up the flow of social funds. At the same time, it proposes to strictly control the statistics and release of real estate data, adjust the tax and fee structure of real estate transactions, and suspend other control measures to collect real estate taxes nationwide. The author believes that under the conditions of a market economy with Chinese characteristics, local governments and functional departments can use the above countermeasures by local conditions to control housing prices, stabilize the real estate economy, and ensure economic stability.

\section{Acknowledgement}

First of all, thanks to Professor Taylor from Johns Hopkins University, by watching Mr. Taylor's lectures. I learned some basic economic knowledge before I go to university, and understood the impact of the US subprime mortgage crisis, the Sino-US trade war and the COVID19 on the world economy, and have a theoretical understanding of the controversial high housing prices in China. Simultaneously, Mr. Taylor's enthusiastic teaching attitude, extensive and profound knowledge, rigorous style of study, and excellence of academic style impressed me deeply and became a model of my efforts to learn.

Secondly, thanks to Olivia, my paper advisor. Olivia has given me a lot of concrete and detailed guidance. 
Olivia's easygoing, approachable, meticulous, and patient nature erased my initial anxiety.

Thanks again to all the people I have mentioned and not mentioned above, especially my parents. I feel proud of having my first paper before I go to university. I appreciate everything I learned and take away in the writing and learning process.

\section{References}

1. International Comparative Study of the Real Estate Industry and the National Economic Development (Shuangle Li). Retrieved August 04, 2020, from http://cdmd.cnki.com.cn/Article/CDMD-10183-2008 019441.htm

2. Home. Retrieved August 04, 2020, from https://coronavirus.jhu.edu/

3. People's Bank of China. Retrieved July 30, 2020, from http://www.mohurd.gov.cn/wjfb/200611/t20061101 165716.html

4. State Council of China. Retrieved July 30, 2020, http://www.gov.cn/zhengce/content/2008-03/28/ content_4797.htm

5. (National Assembly of the PRC). Interim Regulations of the People's Republic of China on Deed Tax Retrieved August 04, 2020. http:// www.gov.cn/gongbao/content/2019/content_537710 4.htm

6. Yan Song. Decision of the Standing Committee of the National People's Congress on Amending the "Individual Income Tax Law of the People's Republic of China". Retrieved August 04, 2020, http://www.gov.cn/xinwen/2018-08/31/content_531 8232.htm 